\title{
ANALISIS PENGARUH EDUPRENEURSHIP DAN MENTORING TERHADAP PENINGKATAN DAYA SAING LULUSAN PERGURUAN TINGGI
}

\author{
Wiriadi Sutrisno $^{1}$ dan Suwiryo Cokro ${ }^{2}$ \\ ${ }^{1}$ Dosen Prograam Studi Pendidikan Ekonomi Universitas Indraprasta PGRI \\ ${ }^{2}$ Alumni Program PS STIE PBM Jakarta \\ Email: wiriadisutrisno@gmail.com
}

\begin{abstract}
Abstrak
Penelitian ini bertujuan untuk menjelaskan bahwa Pemerintah melalui UU SPN No.20 Tahun 2003 telah mengatur bahwa pendidikan nasional merupakan upaya perhatian untuk mengembangkan individu agar mampu membangun self potency mereka melalui proses pembelajaran. Upaya ini bertujuan untuk meningkatkan daya saing para lulusan Perguruan Tinggi di Indonesia, khususnya dalam menghadapi persaingan di pasar global, khususnya dalam MEA. Edupreneurship dan Mentoring merupakan salah satu cara untuk membekali para lulusan memiliki daya saing yang tinggi dengan meningkatkan self potency, baik berupa inovasi, keatifitas dan jiwa kewirausahaan, khususnya dibidang pendidikan. Dengan memiliki jiwa edupreneurship yang dilatih para mentor yang professional, para lulusan perguruan tinggi kelak akan menjadi sang pencipta pekerjaan (job creator) dan bukan menjadi pencari kerja (job seeker). Lebih dari itu para lulusan perguruan tinggi yang memiliki edupreneurship akan sangat membantu program pemerintah dalam mengurangi pengangguran terbuka. Hasil penelitian yang dilakukan terhadap lulusan STIE PBM, menunjukkan bahwa:1) Secara parsial edupreneurship berpengaruh positif terhadap peningkatan daya saing lulusan STIE PBM Jakarta, 2) Secara parsial juga mentoring berpengaruh positif terhadap peningkatan daya saing lulusan STIE PBM Jakarta dan 3) Secara simultan, edupreneruship dan mentoring berpengaruh positif terhadap peningkatan daya saing lulsan STIE PBM, Jakarta.
\end{abstract}

Kata Kunci: Edupenership, Mentoring, Potensi diri, Daya Saing, Perguruan Tinggi.

\section{PENDAHULUAN}

Perguruan Tinggi di Indonesia dari tahun ketahun terus menghasilkan lulusan, yang kemudian menjadi dilema bagi para sarjana. Hal ini disebabkan gelar kesarjanaan dan ijazah yang mereka raih tak lagi jadi jaminan untuk mudah mendapat pekerjaan. Hal ini terlihat dari angka pengangguran terdidik terus mengalami peningkatan akibat kesulitan terserap dunia kerja (Alam , 2016), pengangguran "terdidik" di Indonesia, sejak tahun 2012 sampai dengan tahun 2015 mengalami fluktuasi dan yang cendrung meningkat pada tahun 2016, seperti terlihat pada Tabel 1.

Tabel 1 Tingkat Pengangguran Terdidik Di Indonesia

\begin{tabular}{|c|c|c|c|c|c|}
\hline${ }_{\text {Keterangan }}$ Tahun & 2012 & 2013 & 2014 & 2015 & 2016 \\
\hline $\begin{array}{l}\text { Tingkat Pengangguran } \\
\text { Terdidik (\%) }\end{array}$ & 8,7 & 8,36 & 9,5 & 5,34 & 6,22 \\
\hline
\end{tabular}

(*) Sumber BPS (2016) dalam Cokro (2017) 
Hal ini disebabkan para lulusan tidak memiliki kompetensi yang diinginkan industri. Bahan ajar yang disajikan maupun kompetensi yang diperoleh mahasiswa tidak berhubungan (link) dan sesuai (match) dengan kebutuhan industri (Subali E, 2013). Sehingga para lulusan PT gagal pada saat seleksi penerimaan karyawan, karena kompetensi yang dimiliki tidak selaras (match) dengan kompetensi yang dibutuhkan industri. Dalam mengantisipasi semangkin tingginya tingkat pengangguran, khususnya pada sektor pengangguran terdidik, peran Lembaga Pendidikan sangat penting dalam menghadapi tantangan era perdagangan bebas dengan mempersiapkan lulusannya memiliki kompetensi yang mampu bersaing di pasar bebas, khususnya pada industri yang memiliki standar kebutuhaan SDM yang tinggi. Hal ini sesuai dengan tujuan dari kegiatan pendidikan, yakni untuk meningkatkan potensi manusia melalui proses pembelajaran terpadu. Sebagaimana tercermin pada Undang-undang Sistem Pendidikan Nasional (USPN) No. 20 Tahun 2003 menyebutkan bahwa pendidikan merupakan upaya perhatian untuk mengembangkan individu agar mampu membangun self potency mereka melalui proses pembelajaran.

Sejalan dengan butir butir yang tercantum dalam pada Undang-undang Sistem Pendidikan Nasional (USPN) No. 20 Tahun 2003, STIE PBM mengantisipasi lulusannya, agar tidak ikut memproduksi pengangguran terdidik, telah mengembangkan konsep-konsep dan sikap kewirusahaan dalam proses pembelajaraan secara intensif dan bekelanjutan sampai jenjang S2. Model pembelajaran yang diterapkan STIE PBM sebagai edupreneur menerapkan konsep edupreneurship yang membuat dan mengolah produk pendidikan agar bisa membantu mahasiswa dan dosen, bahkan lembaga pendidikan dapat mendukung proses pembelajaran yang berkelanjutan.

\section{TINJAUAN PUSTAKA}

\section{Pendidikan Perguruan Tinggi}

Ada beberapa pengertian tentang pendidikan perguruan tinggi, yang akan dibahas dalam kajian teoritis tentang Pendidikan Perguruan Tinggi, anatara lain: Webster's New World Dictionary (1962) dalam Sutrisno, W (2017), menjelaskan bahwa:Pendidikan adalah proses pengembangan dan latihan yang mencakup aspek pengetahuan (knowledge), keterampilan (skill) dan kepribadian (character) terutama 
dilakukan dalam suatu bentuk formula kegiatan pendidikan mencakup proses dalam menghasilkan dan transfer ilmu pengetahuan yang dilakukan oleh individu atau organisasi belajar.

Menurut PP 30 Tahun 1990, pasal 1 Ayat 1, tentang tujuan Pendidikan Tinggi, menjelaskan pendidikan tinggi bahwa : "Pendidikan tinggi adalah pendidikan pada jenjang yang lebih tinggi dari pada pendidikan menegah di jalur pendidikan sekolah". Tujuan pendidikan tinggi sendiri merupakan sesuatu hal yang baik untuk dicapai dalam memajukan kehidupan bangasa. Adapun tujuan dari pendidikan tinggi ialah sebagai berikut:

a. Mempersiapkan peserta didik menjadi anggota masyarakat yang memiliki kemampuan akademik dan profesional yang dapat menerapkan, mengembangkan dan menciptakan ilmu pengetahuan, teknologi dan kesenian.

b. Mengembangkan dan menyebar luaskan ilmu pengetahuan, teknologi dan kesenian serta mengoptimalkan penggunaannya untuk meningkatkan taraf hidup masyarakat dan memperkaya kebudayaan nasional. (PP 30 Tahun 1990, Pasal 2, Ayat (1) ).

c. Mengembangkan individu agar mampu membangun self potency mereka melalui proses pembelajaran. Sejalan dengan butir butir yang tercantum dalam pada Undang-undang Sistem Pendidikan Nasional (USPN) No. 20 Tahun 2003

\section{Edupreneurship}

Konsep edupreneurship memungkinkan lembaga pendidikan di banyak negara berobah menjadi edupreneur (Pengusaha Edukasi atau Pengusaha Pendidikan), mengacu pada prinsip prnsip perusahaan yang "mengembangkan produk dan layanan inovatif untuk mengisi peluang yang belum disentuh oleh sekolah yang dikelola pemerintah " (Lips, 2000:2). Istilah Edupreneurship terdiri dari dua kata, yakni Education yang berarti pendidikan dan enterpreneurship yang bermakna kewirausahaan atau kewiraswastaan. Selain dari itu enterpreneurship juga berasal dari bahasa Perancis, entreprendre yang berarti wirausaha/kewirausahaan yang juga diartikan sebagai entreprise yang berarti menyambut tantangan, Fadhilah, (2011:75). Dengan demikian bahwa edupreneurship adalah pendidikan yang mencetak peserta didik yang kreatif 
inovatif, pencipta peluang yang handal, dan pemberani melangkah menyambut tantangan kehidupan.

Dari beberapa definisi diatas, terkandung dua pengertian yang mengandung makna berbeda. Dalam pengertian pertama, edupreneurship lebih banyak berorientasi pada profit yang banyak memberi keuntungan finansial. Definisi kedua lebih umum yaitu semua usaha kreatif dan inovatif sekolah yang berorientasi pada keunggulan. Konsep edupreneurship dalam kajian ini ditekankan pada usaha kreatif atau inovatif yang dilakukan oleh sekolah untuk memperoleh prestasi dan menambah income. Dengan modal prestasi ini, sekolah sedikit demi sedikit akan mengalami kemajuan sampai menjadi sekolah unggul. Dalam konteks ini, unggul tidak dimaknai sebagai evaluasi yang memberi dampak finansial secara langsung tetapi merintis masa depan yang lebih sukses. Setelah menjadi sekolah unggul, peluang dan kesempatan untuk mencari tambahan income semakin mudah didapatkan. Banyak lembaga pendidikan unggul yang ada saat ini cenderung menarik biaya pendidikan yang mahal dari peserta didiknya.

Edupreneurship ingin menempatkan konsep-konsep dan sikap kewirausahaan dalam dunia pendidikan, bukan bertujuan menjadikan mahasiswa sebagai pengusaha, namun lebih pada pembentukan karakter edupreneur dalam bidang pendidikan". Edupreneurship adalah program pelatihan bagaimana mengenalkan konsep-konsep entrepeneurship yang dilengkapi dengan berbagai contoh aplikasinya melalui proses pendidikan.menggunakan berbagai strategi bisnis, bergantung pada sifat produk dan segmen pasar yang telah mereka pilih untuk dilayani.

\section{Mentoring}

Zachary (2005), dalam Sutrisno, W (2017) menjelaskan bahwa mentoring merupakan "Hubungan pembelajaran timbal balik dan kolaaboratif antara dua orang atau lebih yang memiliki tanggungjawab dan tanggunggugat/akuntabilitas yang sama untuk membantu mentee bekerja mencapai sasaran pembelajaran yang jelas dan didefinisikan bersama”. Sedangkan Crawford (2003), mentoring merupakan "Hubungan interpersonal dalam bentuk kepedulian dan dukungan antara seseorang yang berpengalaman dan berpengetahuan luas dengan seseorang yang kurang berpengalaman maupun yang pengetahuannya lebih sedikit”. 
Dari definisi di atas, dapat disimpulkan bahwasannya mentoring adalah suatu proses peningkatan kualitas diri yang dilakukan secara interpersonal baik dalam hal pendidikan dan pekerjaan melalui pendekatan emosional diantara pementor dengan para mentee-nya. Terlepas dari pengertian-pengertian diatas, dapat dilakukan identifikasi beberapa ciri mentoring sebagai kerangka rujukan umum untuk memahami pengertian mentoring sebagai berikut:

a. Mentoring mencerminkan hubungan yang unik antar individu.

b. Mentoring merupakan kemitraan pembelajaran. Mesikipun sasaran mentoring mungkin berbeda lintas setting maupun hubungan, namun hampir semua hubungan mentoring melibatkan penguasaan pengetahuan.

c. Mentoring merupakan proses didefinisikan oleh jenis dukungan yang disediakan mentor kepada mentee atau protege.

d. Mentoring hubungannya bersifat timbal balik, namun tidak seimbang. Meskipun mentor mungkin mendapat manfaatdari hubungan itu, namun sasaran utamanya adalah pertumbuhan dan perkembangan mentee.

e. Mentoring hubungannya itu dinamis, hubungan itu berubah seiring perjalanan waktu dan dampak mentoring juga bertambah seiring dengan waktu.

\section{Daya Saing Lulusan Perguruan Tinggi}

Muhardi (2007: 35), menjelaskan bahwa daya saing adalah " efektivitas suatu organisasi di pasar persaingan, dibandingkan dengan organisasi lain yang menawarkan produk atau jasa-jasa yang sama atau sejenis. Kemudian ditambahkan oleh Imam, dkk (2008) menyatakan bahwa daya saing merupakan competitive yang memiliki kekuatan untuk berusaha menjadi unggul yang dilakukan seseorang/institusi di pasar persaingan yang menawarkan produk atau jasa-jasa yang sama, dimana kelompok/institusi memiliki kemampuan, kinerja, talenta, atau prestasi untuk menunjukkan hasil lebih baik, lebih cepat atau lebih bermakna dari seseorang/institusi lain.

\section{METODE}

Metode yang digunakan dalam penelitian ini adalah metode survey dengan analisis regresi berganda. Peneltian ini menggunakan pengumpulan data angket yang kemudian disusun berdasarkan instrumen variable dengan skala likert. Kemuadian dilakukan proses uji vaiditas dan reliabilitas yang selanjutnya uji 
hipotesinya menggunakan Uji F. dengan signifikansi alpa 5\%. Selanjutnya Pengujian hipotesis dilakukan dengan bantuan IMB SPSS Versi 20, Augusty, F (2006).

\section{HASIL DAN PEMBAHASAN}

Pembahasan hasil penelitian ini meliputi Analisa Statistika Deskriptif, Analisis Butir Instrument, Analisis Statistika Infrensial, Analisis Regresi.

\section{Analisis Statistika Deskriptif}

Dalam penelitian menhkaji dua variabel independen dan satu variabel dependen, yakni variabel independen edupreneurship (X1) dan mentoring (X2) sedangkan variabel daya saing lulusan STIE PBM adalah variabel dependen (Y). Unit analisis penelitian ini adalah 30 sample size yang merupakan stake holder STIE PBM, yakni unsur pimpinan, dosen dan mahasiswa.. Deskripsi data secara keseluruhan yang diolah dengan menggunakan progam SPSS versi 20.variabel penelitian tampak pada Tabel 2.

Tabel 2 Statistik Deskriptif Variabel Penelitian

Descriptive Statistics

\begin{tabular}{|c|c|c|c|c|c|c|c|c|c|c|c|c|c|}
\hline & N & Range & Minimum & Maximum & Sum & \multicolumn{2}{|c|}{ Mean } & $\begin{array}{c}\text { Stdo. } \\
\text { Deviation }\end{array}$ & Variance & \multicolumn{2}{|c|}{ Skewness } & \multicolumn{2}{|c|}{ Kurtosis } \\
\hline & Statistic & Statistic & Statistic & Statistic & Statistic & Statistic & Std. Error & Statistic & Statistic & Statistic & Std. Error & Statistic & Std. Error \\
\hline Edupreneurship & 30 & 37,00 & 41,0 & 78,00 & 1918,00 & 63,9333 & 1,83073 & 10,02732 & 100,547 & $; 742$ &, 427 &,- 221 &, 833 \\
\hline Mentoring & 30 & 28,00 & 49,0 & 77,00 & 1957,00 & 65,2333 & 1,43494 & \begin{tabular}{|l|}
7,85947 \\
\end{tabular} & 61,771 & -932 &, 427 & ,121 &, 833 \\
\hline Daya Saing & 30 & 35,00 & 43,0 & 78,00 & 1922,00 & 64,0667 & 2,23449 & 12,33881 & 149,789 & -594 &, 427 & $-1,113$ &, 833 \\
\hline Valid N (listwise) & 30 & & & & & & & & & & & & \\
\hline
\end{tabular}

Sumber: Output Olah Data SPSS v.20 dalam Cokro (2017)

Output tampilan SPSS versi 20 menunjukkan jumlah responden (N) ada 30, variabel Edupreneurship \& Daya Saing memiliki hasil maximum sebesar 78, variabel mentoring memiliki hasil 77 poin, sedangkan untuk nilai minimum lebih bervariasi dengan tingkat terendah ada pada variabel X1 (Edupreneurship) sebanyak 41 poin. Rata - rata butir poin tiap variabel dari 30 responden memiliki angka berkisar 63 - 65 poin. Skewness mengukur kemencengan dari data dan kurtosis mengukur puncak dari distribusi data. Data yang terdistribusi secara normal mempunyai nilai skewness \& kurtosis mendekati nol.

\section{Analisis Statistika Infrensial.}




\section{Uji Instrumen Penelitian}

Sebelum instrumen diujikan ke objek penelitian, peneliti melakukan uji validitas instrumen dan reliabilitas terlebih dahulu. Peneliti melakukan dua jenis validitas yaitu:

Uji Validitas Data

Pengujian validitas tiap butir digunakan analisis item, yaitu mengkorelasikan skor tiap butir dengan skor total (corrected item total correlation) yang penyelesaiannya dibantu dengan menggunakan program SPSS V. 20. Uji validitas dengan membandingkan antara rhitung dan rtabel dengan menggunakan rumus koefisien korelasi product moment yang dikemukakan Pearson, dengan kriteria berikut ini :

Jika rhitung > rtabel maka pernyataan dapat dinyatakan valid

Jika rhitung < rtabel maka pernyataan dapat dinyatakan tidak valid

Sedangkan untuk mendapatkan " $\mathrm{r}$ " tabel dilakukan dengan tabel $\mathrm{r}$ product moment, yaitu menentukan alpha $(\alpha)=0,05$ kemudian $n$ (sampel) $=30$ orang, sehingga didapat nilai rtabel sebesar 0,361. Dari hasil analisis validitas, dari 17 butir insrumen, diperoleh hasil bahwa semua butir pertanyaan pada variabel edupreneurship (X1), monitoring (X2) dan daya saing lulusan STIE PBM (Y), menunjjukan nilai rhitung $\geq$ rtabel. Dengan demikian ke tiga variabel dinyatakan valid.

Uji Reliabilitas Instrumen

Uji Reliabilitas instrumen bertujuan untuk mengukur tingkat keajegan (konsistensi) suatu pertanyaan, yakni sejauh mana suatu pertanyaan dapat dipercaya untuk menghasilkan skor yang ajeg. Relatif tidak berubah walaupun diteskan pada situasi yang berbeda-beda.

Menurut Triton, dalam Sutrisno (2017), skala Alpha Cronbach's dikelompokkan ke dalam 5 kelas sebagai berikut:

$0-0,20=$ Kurang Reliabel

0,21-0,40 = Agak Reliabel

0,41-0,60 = Cukup Reliabel

$0,61-0,80=$ Reliabel

$0,81-1,0=$ Sangat Reliabel 
Research and Development Journal Of Education

Vol. 5 No. 1 Oktober 2018

ISSN 2406-9744

Nilai Cronbach Alpha setiap variabel memiliki nilai di atas 0,9 itu berarti semua variabel sangat reliabel. yakni edupreneurship (0,964.), mentoring $(0,948)$ dan daya saing. $(0,983)$.

Uji Persyaratan Analisis

Tabel 3. Homogenitas

\begin{tabular}{|l|l|c|c|l|}
\hline No & $\begin{array}{c}\text { Varians data Y Berdasarkan } \\
\text { Pengelompokan Data }\end{array}$ & Signifikasi & $\begin{array}{l}\propto \\
=\mathbf{0 , 0 5}\end{array}$ & Kesimpulan \\
\hline 1 & Edupreneurship (X1) & 0,270 & 0,05 & Homogen \\
\hline 2 & Mentoring (X2) & 0,180 & 0,05 & Homogen \\
\hline
\end{tabular}

Tabel 4. Linieritas

\begin{tabular}{|c|l|c|c|c|}
\hline $\begin{array}{c}\text { Variabel } \\
\text { Indemendent }\end{array}$ & $\begin{array}{c}\text { Variabel } \\
\text { Dependent }\end{array}$ & $\begin{array}{c}\text { Hasil Pengujian } \\
((\boldsymbol{\alpha})\end{array}$ & Sig & Keputusan \\
\hline $\mathrm{X} 1$ & $\mathrm{Y}$ & 0,05 & 0,917 & Linear \\
\hline $\mathrm{X} 2$ & $\mathrm{Y}$ & 0,05 & 0,816 & Linear \\
\hline
\end{tabular}

(*) Sumber: Output Olah Data SPSS v.20 (2017)

Analisis Regresi.

Analisis Regresi dilakukan melalui pendekatan persamaan regresi linear berganda, dengan menggunakan alat olah data SPSS v.20, seperti pada tabel 5. Berdasarkan hasil uji analisis regresi didapatkan persamaan $\mathrm{Y}=35,388+0,620$ $\mathrm{X}_{1}+3,299$

Dari persamaa regresi linear tersebut dapat diuraikan hasil analisis sebagai berikut:

1. Dari data di atas diperoleh persamaan regresi yang terbentuk antara X1 dan $\mathrm{Y}$ adalah $\mathrm{Y}=35,388+0,620 \mathrm{X}_{1}$; artinya jika $\mathrm{X}_{1}$ diabaikan maka $\mathrm{Y}$ sebesar 35,388 dan setiap penambahan 1 point pada $\mathrm{X}_{1}$ akan memberikan tambahan Y sebesar 0,620.

2. Koefisien regresi variabel Mentoring $\left(\mathrm{X}_{2}\right)$ sebesar 3,299 artinya jika variabel Mentoring mengalami kenaikan 1\% maka variabel Daya Saing akan mengalami kenaika sebesar 3,299 dengan asumsi variabel Independen yang lain (Edupreneurship) nilainya tetap.

Dari uji F diketahui nilai probabilitas signifikansi variabel Independen secara simultan adalah $0,000<0,05$. Hasil ini menyatakan adanya hubungan 
antara variabel Edupreneurship dan Mentoring terhadap Daya Saing. Hal ini diperkuat dengan memperbandingkan $\mathrm{F}_{\text {hitung }}>$ Ftabel yaitu 19,408 > 4,210. Dari tampilan Output SPSS model summary besarnya adjusted $\mathrm{R}$ adalah 0,559 hal ini berarti 55,9\% variasi Daya Saing dapat dijelaskan oleh variasi dari ke dua variabel independen Edupreneurship \& Mentoring. Sedangkan sisanya 44,1\% dijelaskan oleh sebab sebab yang lain diluar model. Standar Error of Estimate (SEE) sebesar 8,12401. Makin kecil nilai SEE akan membuat model regresi semakin tepat dalam memprediksi variabel dependen.

Berdasarkan analisis statistik secara parsial menunjukan bahwa edupreneurship memberikan pengaruh terhadap daya saing lulusan STIE PBM dengan nilai $t_{\text {hitung }}>$ sig yaitu 2,723 $>0,011$. Dengan demikian hipotesis yang menyatakan terdapat pengaruh yang signifikan antara edupreneurship daya saing lulusan STIE PBM dapat diterima. Pada variabel mentoring tidak terdapat pengaruh terhadap daya saing lulusan STIE PBM dengan nilai $t_{\text {hitung }}$ lebih kecil daripada nilai sig. yaitu $-1,662<0,108$.

\section{SIMPULAN}

Berdasarkan data yang diperoleh dari hasil penelitian yang dilakukan maka dapat ditarik kesimpulan sebagai berikut :

1. Terdapat pengaruh positif dan signifikan eduprenurship terhadap daya saing lulusan STIE PBM.

2. Tidak terdapat pengaruh mentoring terhadap daya saing lulusan STIE PBM.

3. Terdapat pengaruh positif dan signifikan edupreneurship dan mentoring secara bersama-sama terhadap daya saing STIE

\section{SARAN}

Berdasarkan pembahasan, kesimpulan, dan implikasi di atas maka dapat diberikan beberapa saran sebagai berikut :

1. Kepada Para Pimpinan STIE PBM.

Para pimpinan harus mendukung program edupreneurship di kampus STIE PBM agar para lulusan memiliki nilai daya saing yang tinggi dan sekaligus akan meningkatkan citra kualitas pendidikan di STIE PBM. Dengan citra yang menjadi image bagi masyarakat akan berdampak semangkin banyak minat melanjutkan pendidikan tinggi di STIE PBM. Denga cara inilah profit akan dicapai. 
2. Kepada Para Dosen

Para dosen STIE PBM harus selalu melakukan up grading dan refreshing tentang know how dalam mengoperasikan kewirausahaan di dunia pendidikan, agar mahasiswa bisa mengaplikasikan teori teori yang dipelajari guna meningkatkan daya saing mereka dalam menghadapi persaingan yang tinggi di pasar tenaga kerja dan dunia usaha.

\section{DAFTAR PUSTAKA}

Adam, N (2006), Regional Development and Spatial Planning in an Enlarge European Union, Aldershot: Ashgate.

Ahmad, Sabri, 2007, Strategi Belajar Mengajar Mikro Teaching, Quantum. Teaching, Ciputat.

Augusty, Ferdinand, (2006), Metode Penelitian Manajemen: Pedoman Penelitian, untuk skripsi, Tesis dan Disertai Ilmu Manajemen. Semarang: Universitas Diponegoro.

Badan Pusat Statistik. (2011). Pengangguran terbuka menurut pendidikantertinggi yang ditamat kan, Sumber: Survei Angkatan Kerja Nasional (SAKERNAS)

BPPN (2014), Peringkat Indikator, SJR, Scimago Journal \& Country Rank

BPS (2016), Perkembangangan Pengangguran Terdidik Di Indonesia Tahun 2016

Cokro, Suwiryo, (2017), Pengaruh Edupreneurship dan Mentoring terhadap Peningkatan Daya Saing Lulusan STIE PBM, Jakarta (Tesis), Jakarta

Crawford, Muchael. 2010. A Fifth Discipline Resource: A Practicioner's Guide Using Team Learning within Mentoring Program. The Union Institute and University Graduate College. Cincinnati, Ohio.

Departemen Pendidikan Nasional melalui Surrat Keputusan Menteri Pendidikan No. 232/U/2000 tentang Pedoman Penyusunan Kurikulum Pendidikan dan Penilaian Hasil Belajar Mahasiswa

Fadhilah, (2011) Pendidikan Entrepreneurship Berbasis islam dan Kearifan Lokal, Jakarta:DIadit Media Press, 2011, hal. 75.

Gurino Prasetyo (2014), Mentoring Program Implementation In Forming Character Of Student At SMA N 5 Yogyakarta, an Academic Journal. 
Research and Development Journal Of Education

Vol. 5 No. 1 Oktober 2018

ISSN 2406-9744

Lips, Carrie (2000), Edupreneurs: A Survey of For-profit Education, PenerbitCato Institute

Peraturan Pemerintah Republik Indonesia No. 19 tahun 2005, tentang Standar Nasional Pendidikan

Menurut PP 30 Tahun 1990, tentang Tujuan Pendidikan Tinggi, Republik Indonesia

Muhardi (2007), Strategi Operasi Untuk Keunggulan Bersaing. Yogyakarta:Garaha Pustaka.

Permendikbud No. 54/2013 tentang Standar Kompetensi Lulusan (SKL)

Permendikbud Republik Indonesia Nomor 49 Tahun 2014 Tentang Standar Nasional Pendidikan Tinggi (SNPT)

Permendikbud Republik Indonesia No. 73 Tahun 2013 tentang Penerapan Kerangka Kualiikasi Nasional Indonesia Bidang Pendidikan Tinggi

Permendiknas No 41 tahun 2007, tentang Standar Proses Utuk Satuan Pendidikan Dasar Dan Menengah

Perpres No. 08 tahun 2012 tentang Kerangka Kualifikasi Nasional Indonesia

Siti Munjilatul, Hasana (2012) Peluang Dan Daya Saing Lususan Pendidikan Ekonoomi Universitas Negeri Yogyakarta di Paasar Tenaga Kerja Pegawai Negeri Sipil (PNS) Guru SMA Provinsi Daerah Istimewa Yogyakarta . thesis, Negeri Yogyakarta.

Sutrisno, Wiriadi (2017), Edupreneurship Sebagai Pemerkaya Kometensi Untuk Memperkuat Daya Saing Lulusan Perguruan Tinggi di Indonesia, Proceeding, LP2M Universitas Indraprasta, Jakarta, ISBN: 978.603.50181.0.7.

Undang-Undang Sistem Pendidikan Nasional (USPN) No. 20 Tahun 2003 Tentang Sistem Pendidikan Nasional

\section{Sumber Web Site}

Alam, Hermansyah, (2016), Angka-pengangguran-terdidik-meningkat, Institut Teknologi Medan (ITM) Jalan Gedung Arca Medan, http://beritasore.com/2016/06/27/diakses27 Juni 2017

Imam M dkk (2008), Peningkatan Daya Saing Lulusan Universitas Terbuka(UT) Melalui Penyelenggaraan Pendidikan Tinggi Jarak Jauh (PPTJJ) yang BerkualitasInternasionalSurabaya.http://utsurabaya.files.wordpress com/2010/07/daya-saing-lulusan-ut.pdf, diakses Juli 2017. 